\title{
Estimation of Ecological Compensation Rates for Transboundary Watershed Based on Emissions Trading
}

\author{
_A Case of Songhua River Basin \\ Li Wanhong, a , Wang Fuyao ${ }^{1, ~ b, ~ * ~}$
}

\author{
${ }^{1}$ School of Economics and Management, Harbin Engineering University, Harbin 150001, China \\ aliwanhong@hrbeu.edu.cn, bwangfuyao9328@163.com
}

Keywords: Songhua River basin, emission rights, ecological compensation standard

\begin{abstract}
Based on the theory of emissions trading, this paper constructs a panel data model based on Kuznets curve (EKC) and ecological compensation standard calculation model. Taking data of seven cities from Songhua River basin such as Jilin, Changchun, Songyuan, Qiqihar, Harbin, Qitaihe, Jiamusi, the paper also calculates their ecological compensation rates in 2004 and 2015 based on the trading of emission rights, and does longitudinal analysis of the ecological compensation standards of Changchun and Harbin. The results show that cities with transboundary basins should follow the principle of "who pollutes who pays", and cities that overuse the right to emit pollutants should pay more ecological compensation, while the economically viable cities will receive corresponding ecological compensation, which will help clear cross-border river basin water pollution control responsibilities, and improve pollution control efficiency.
\end{abstract}

\section{Literature Review}

Due to the fluidity of water resources and the characteristics of public resources, watershed management involves the vertical affiliation between the upper and lower levels of government and the horizontal parallel relationship between governments at the same level. This complex multi-tiered relationship leads to controversy over water quality issues in the upper and lower reaches of the basin. Some scholars think that ecological compensation in watersheds actually means paying for ecosystem services, more like a transaction or payment behavior between upstream and downstream areas that is mostly used to compensate and encourage resource owners to improve their management practices and thereby ensure long-term maintenance and provision of ecosystem services. Existing literature in the study of watershed eco-compensation mode mainly bases on the principle of "who compensates and compensates who", and is divided into government compensation, market compensation, quasi-market compensation, social compensation and self-compensation. From the perspective of measures and diversification of models, the operability of ecological compensation measures in transboundary watersheds needs to be further studied ${ }^{[1]}$.

\section{Basic Thinking and Model}

According to the theory of environmental economics, this paper assumes that there is an "Environmental Kuznets Curve" between the level of economic development in China and the amount of industrial waste water discharged ${ }^{[2]}$ (Wu Zhaopu, Wang Qian, 2010). This paper takes seven cities (Jilin City, Changchun City, Songyuan City, Qiqihar City, Harbin City, Qitaihe City, Jiamusi City (hereinafter abbreviated as "city" for short)) in Songhua River Basin as observation samples. By building a functional relationship between regional economic development level and industrial waste water discharge, and based on this model, we estimate the overused or abandoned emission rights in sample (Changchun and Harbin), and the ecological compensation rates that need to be paid or obtained by cities due to their emission rights. 


\subsection{Emission measurement model}

\subsubsection{Basic model}

This paper assumes that there is a certain functional relationship between per capita GDP in a certain region and per capita industrial waste water discharge:

$$
r \text { Warter }=f(r G D P)
$$

rWater stands for actual per capita industrial waste water discharge (Ton / person), rGDP for GDP per capita of the region (Yuan / person). We can use equation (1) to calculate the theoretical per capita industrial waste water discharge, or

$$
r \text { Water }_{i}^{*}=f\left(r G D P_{i}\right)
$$

In the equation, $r$ Water $_{i}^{*}$ represents the theoretical per capita industrial waste water discharge of region $i$ (Ton / person).

Since $r$ Water $_{i}$ can be obtained by referring to the statistical data, emission rights of region $i$ can be obtained by the difference from $r$ Water $_{i}^{*}$ and rWater $_{i}$, or

$$
\Delta r \text { Water }_{i}=\text { rWater }_{i}^{*}-\text { rWater }_{i}
$$

In that, $\Delta r$ Water ${ }_{i}$ stands for the overused or loss of emission rights (Ton / person) of region $i$. When $r$ Water $_{i}>r$ Water $_{i}^{*}$, emission rights is overused, the corresponding pollution fee should be paid. When $r$ Water $_{i}<$ Water $_{i}^{*}$, emission rights is saved, and should be compensated accordingly.

\subsubsection{EKC based regression model}

Du Jiang and Luo Jun (2013) argue that there is a similar Environmental Kuznets Curve(EKC) between economic growth and the environment ${ }^{[3]}$, and verified its existence by using the following simple equation,

$$
r W a t e r_{i t}=\alpha_{i t}+\beta_{1} r G D P_{i t}+\beta_{2} r G D P_{i t}^{2}+\beta_{3} z_{i t}+\varepsilon_{i t}
$$

In this equation, $z$ is for other variables that affect the quality of the environment, $\beta_{n}(n=1,2,3)$ for estimated coefficient, $a$ for fixed intercept item, $t$ for year, and $\varepsilon$ for error term.

Grossman and Krueger (2000) incorporate industrial scale effects, industrial structure effects and technological innovation effects into the traditional EKC model as control variables and constructs the following extended logarithmic EKC model ${ }^{[4]}$ :

$$
\ln r \text { Water }_{i t}=\alpha_{i t}+\beta_{1} \ln r G D P_{i t}+\beta_{2} \ln \left(r G D P_{i t}\right)^{2}+\beta_{3} \ln s E f f e c t_{i t}+\beta_{4} \ln \text { Effect }_{i t}+\beta_{5} \ln t \text { Effect }_{i(t-1)}+\varepsilon_{i t}
$$

sEffect represents industrial scale effects measured by regional industrial output value and adjusted according to the gross industrial output index; iEffect is for industrial structure effect measured by GDP proportion of secondary industry, while $t E f f e c t$ for technological innovation effect, selects a lagged number of regional patents to measure ${ }^{[5]}$ (Sun Zhenjia, Zhang Xiangxian, 2015).

\subsection{Ecological compensation standard calculation model}

The following formula can be used to further determine the ecological compensation standards.

$$
E_{\text {compensation }}=P_{\text {water }} \times T_{\text {population }} \times \Delta r \text { Water }_{i}
$$

$E_{\text {compensation }}$ means ecological compensation standard (Yuan), $P_{\text {water }}$ for emission right price (Yuan / ton), and $T_{\text {population }}$ for total population (Person). This paper uses the calculation results of emission price (6.44 Yuan/ton) of Jin Shuai (2011) ${ }^{[6]}$. 


\section{Demonstration Calculation of Ecological Compensation Standard in Songhua River Basin}

\subsection{Data source analysis}

This paper collects the data of the above seven sample cities from 2004 to 2015 and calculates the ecological compensation standard of Songhua River Basin. Among which, GDP per capita, total industrial waste water discharge, total industrial output value and the total population at the end of each city come from the "China City Statistical Yearbook". We first eliminate the impact of each city's price level (replaced by the GDP deflator (the year of $2000=100$ )) and then calculate the annual real GDP of each city. Description of the original data is shown in Table 1.

Table 1 Original data description

\begin{tabular}{cccccc}
\hline Variables & Observation & \multirow{2}{*}{ Median } & $\begin{array}{c}\text { Standard } \\
\text { deviation }\end{array}$ & $\begin{array}{c}\text { Maximum } \\
\text { value }\end{array}$ & $\begin{array}{c}\text { Minimum } \\
\text { value }\end{array}$ \\
\hline rWater (Ton / person) & 84 & 13.196 & 10.23828 & 43.530 & 2.590 \\
rGDP (Person / yuan) & 84 & 18999.610 & 9561.978 & 46317.530 & 5437.121 \\
sEffect (100 million yuan) & 84 & 843.740 & 867.8793 & 3477.427 & 27.957 \\
iEffect (\%) & 84 & 0.423 & 0.112845 & 0.662 & 0.199 \\
tEffect (Piece) & 84 & 2586.393 & 4742.223 & 24787.000 & 43.000 \\
\hline
\end{tabular}

Fig.1 shows the per capita industrial waste water discharge trends of Jilin, Changchun, Songyuan, Qiqihar, Harbin, Qitaihe, Jiamusi from 2004-2015.

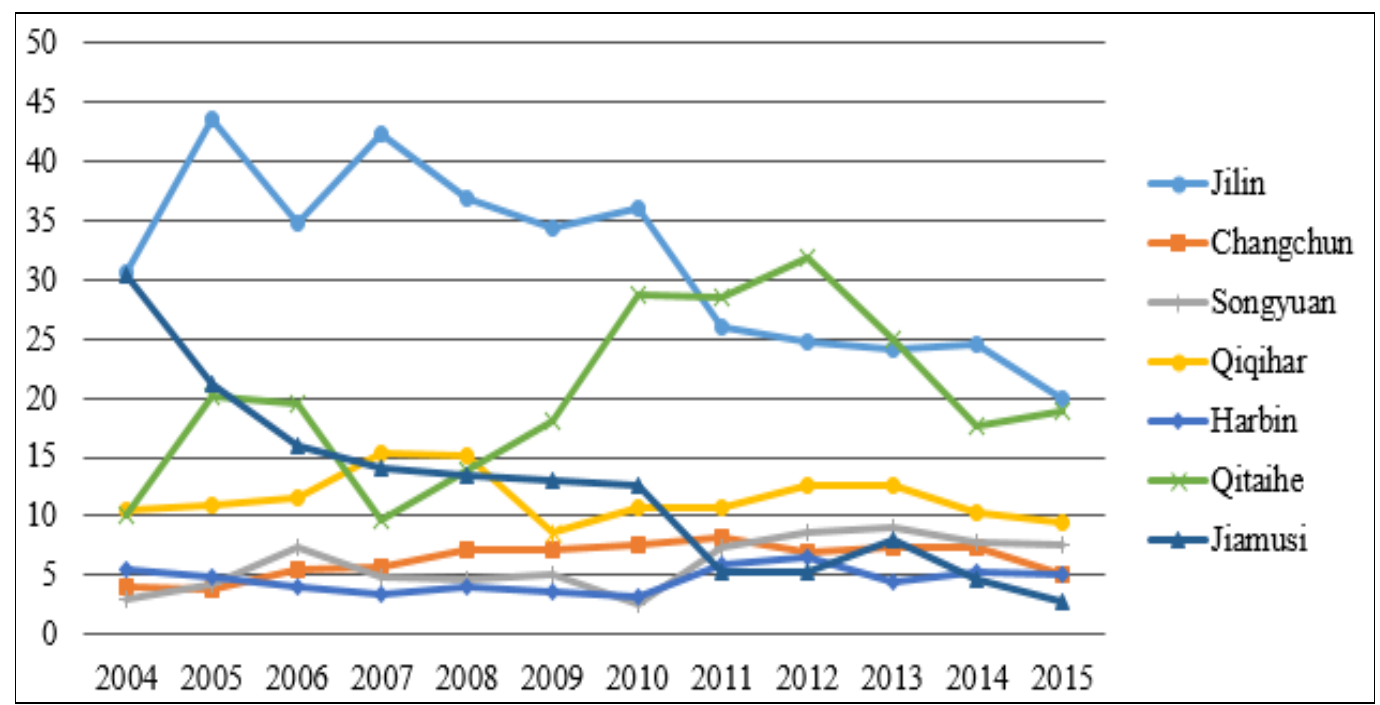

Fig.1 Per Capita Industrial Waste Water Emissions Trends

As can be seen from Fig.1, the numbers of Jilin City, Jiamusi City and Qitaihe City fluctuate greatly. The figure of Jilin City and Jiamusi City drops while that of Qitaihe comes up. The rest four cities show more flat curve.

\subsection{Model estimation and calculation}

Through unit root test and co-integration test function of Eviews 8.0 software on panel data, we can determine that the panel data model passes the smoothness test, that is, there is no spurious regression and the long-term stable co-integration relationship among the five variables. For small samples, we select individual fixed-effect model to estimate the variables. As can be seen from Table 2, except that the intercept item $\mathrm{P}$ value is not significant, other coefficients and index estimation results are more ideal. Therefore, it is feasible to use the individual fixed effect model to deal with the relationship between per capita GDP and per capita industrial waste water discharge. 
Table 2 Processing results of individual fixed effects model

\begin{tabular}{ccccc}
\hline Variable & Coefficient & $\begin{array}{c}\text { Standard } \\
\text { error }\end{array}$ & T value & P value \\
\hline $\mathrm{c}$ & -0.4512 & 1.8412 & -0.2451 & 0.8071 \\
rGDP & 0.9961 & 0.4146 & 2.4028 & 0.0188 \\
$\ln$ sEffect & -1.4446 & 0.3946 & -3.6614 & 0.0005 \\
$\ln$ iEffect & 0.8685 & 0.4387 & 1.9791 & 0.0516 \\
$\ln$ tEffect & 0.4018 & 0.1332 & 3.0166 & 0.0035 \\
\hline fixed effect & & & \\
Jilin & 2.1260 & & & \\
Changchun & 0.2995 & & & \\
Songyuan & -0.7472 & & & \\
Qiqihar & 0.7712 & & & \\
Harbin & -0.3970 & & & \\
Qitaihe & -1.6668 & & & \\
Jiamusi & -0.3859 & & & \\
\hline $\mathrm{R}^{2}: 0.9023$ & Adj $\mathrm{R}^{2}: 0.8889$ & & \\
$\mathrm{D}$. W.: 1.0594 & & & & \\
\hline
\end{tabular}

Based on the results of formula (5) and Table 2, the overused or saved emission rights can be obtained. Taking the capital cities of Changchun and Harbin for example, the $r$ Water ${ }^{*}$ and $r$ Water in 2004-2015 are shown in Fig.2 and Fig.3. Among them, Changchun in 2004-2007, and 2015, rWater $<$ rWater $^{*}$, the corresponding ecological compensation can be obtained, in 2008-2014 $r$ Water $>$ rWater ${ }^{*}$, then need to pay ecological compensation. Likewise, there is also a discrepancy between $r$ Water ${ }^{*}$ and $r$ Water in Harbin in 2004-2015, so payment or acquisition of ecological compensation should be made accordingly.

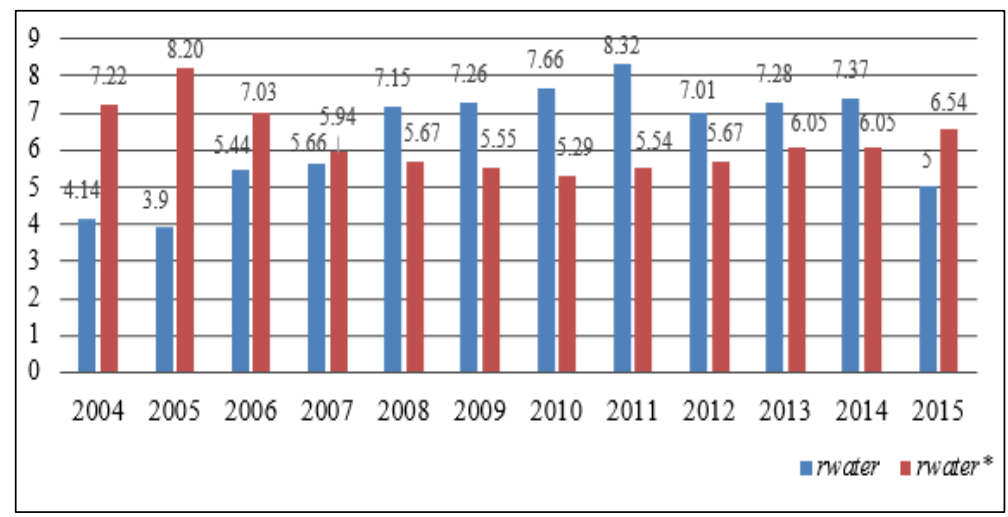

Fig.2 Per Capita Industrial Waste Water Discharge of Changchun (tons / person)

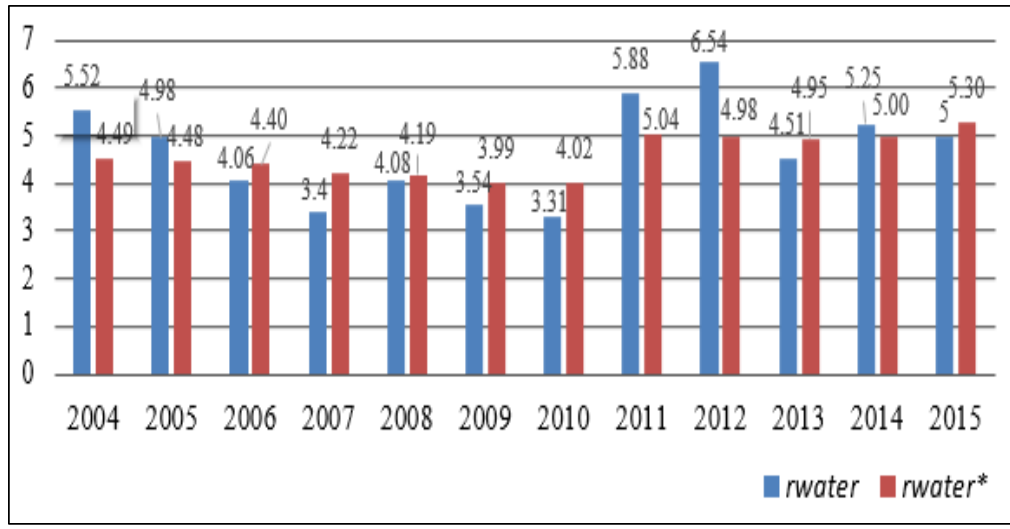

Fig.3 Per Capita Industrial Waste Water Discharge of Harbin (tons / person) 


\subsection{Ecological compensation standard calculation}

Taking Changchun and Harbin, 2004 and 2015 as examples and combining with formula (6), the ecological compensation for the sample cities is shown in Table 3 and Table 4.

Table 3 Ecological compensation rates for Changchun and Harbin from 2004-2015

\begin{tabular}{|c|c|c|c|c|c|c|}
\hline \multirow[b]{2}{*}{ Year } & \multicolumn{3}{|c|}{ Changchun } & \multicolumn{3}{|c|}{ Harbin } \\
\hline & $\begin{array}{c}\text { Overused } \\
\text { emission } \\
\text { right } / 10,000 \\
\text { tons }\end{array}$ & $\begin{array}{c}\text { Abandoned right to } \\
\text { discharge/10,000 } \\
\text { tons }\end{array}$ & $\begin{array}{c}\text { Compensation } \\
\text { standard/ } 100 \\
\text { million yuan }\end{array}$ & $\begin{array}{c}\text { Overused } \\
\text { emission } \\
\text { right } / 10,000 \\
\text { tons }\end{array}$ & $\begin{array}{l}\text { Abandoned right } \\
\text { to } \\
\text { discharge } / 10,000 \\
\text { tons }\end{array}$ & $\begin{array}{c}\text { Compensation } \\
\text { standard/ } 100 \\
\text { million yuan }\end{array}$ \\
\hline 2004 & - & 2229.920 & 1.4361 & 999.337 & - & -0.6436 \\
\hline 2005 & - & 3147.910 & -2.0273 & 489.236 & - & 0.3151 \\
\hline 2006 & - & 1174.510 & -0.7564 & - & 332.307 & -0.2140 \\
\hline 2007 & - & 206.486 & -0.1330 & - & 807.550 & -0.5200 \\
\hline 2008 & 1115.089 & - & 0.7181 & - & 107.896 & -0.0695 \\
\hline 2009 & 1296.695 & - & 0.8351 & - & 447.823 & -0.2884 \\
\hline 2010 & 1798.310 & - & 1.1581 & - & 704.077 & -0.4534 \\
\hline 2011 & 2114.324 & - & 1.3616 & 836.073 & - & 0.5384 \\
\hline 2012 & 1017.571 & - & 0.6553 & 1552.518 & - & 0.9998 \\
\hline 2013 & 924.5953 & - & 0.5954 & - & 439.453 & -0.2830 \\
\hline 2014 & 995.2276 & - & 0.6409 & 244.813 & - & 0.1577 \\
\hline 2015 & - & 1160.898 & 0.7476 & - & 288.411 & 0.1857 \\
\hline
\end{tabular}

As can be seen from Table 3, in the 12-year sample study period, Changchun overused emission rights for more than seven years and saved emission rights for five years, while Harbin overused emission rights for more than five years and saved emission rights for seven years. As a result, the annual emission of industrial waste water may increase or decrease due to the impact of industrial scale, industrial structure, and technological innovation in environmental protection and other factors in various cities. As a result, the emission rights also change accordingly.

Table 4 Ecological compensation rates of cities in Songhua River Basin in 2004 and 2015

\begin{tabular}{c|c|c|c|c|c|c}
\hline \multirow{2}{*}{ City } & \multicolumn{3}{|c|}{ Year of 2004 } & \multicolumn{3}{c}{ Year of 2015 } \\
\cline { 2 - 8 } & $\begin{array}{c}\text { Overused } \\
\text { emission } \\
\text { right/10,000 } \\
\text { tons }\end{array}$ & $\begin{array}{c}\text { Abandoned } \\
\text { right to } \\
\text { discharge/10,00 } \\
\text { 0 tons }\end{array}$ & $\begin{array}{c}\text { Compensation } \\
\text { standard/100 } \\
\text { million yuan }\end{array}$ & $\begin{array}{c}\text { Overused } \\
\text { emission } \\
\text { right/10,000 } \\
\text { tons }\end{array}$ & $\begin{array}{c}\text { Abandoned } \\
\text { right to } \\
\text { discharge/ } \\
10,000 \text { tons }\end{array}$ & $\begin{array}{c}\text { Compensation } \\
\text { standard/100 } \\
\text { million yuan }\end{array}$ \\
\hline Jilin & - & 1394.478 & 0.8980 & - & 4228.301 & 2.7230 \\
\hline Changchun & - & 2229.920 & 1.4361 & - & 1160.898 & 0.7476 \\
\hline Songyuan & - & 342.552 & 0.2206 & 333.684 & - & -0.2149 \\
\hline Qiqihar & - & 3626.509 & 2.3355 & 137.348 & - & -0.0885 \\
\hline Harbin & 999.337 & - & -0.6436 & - & 288.411 & 0.1857 \\
\hline Qitaihe & - & 675.229 & 0.4348 & - & 145.443 & 0.0937 \\
\hline Jiamusi & 3862.980 & - & -2.4878 & - & 1259.015 & 0.8108 \\
\hline
\end{tabular}

As can be seen from Table 4, Harbin and Jiamusi switched from overusing in 2004 to saving emission rights by 2015, thus obtaining ecological compensation of 18,570,000 yuan and $81,080,000$ yuan respectively. On the contrary, Songyuan and Qiqihar should pay ecological compensation of 21,490,000 yuan and 8,850,000 yuan. Jilin, Changchun and Qitaihe saved emission rights, thus obtaining ecological compensation of 272,300,000 yuan, 74,760,000 yuan and 9,370,000 yuan respectively.

\section{Conclusion}

Based on the theory of emissions trading, the results show that transboundary river basins should follow the principle of "who pollutes who pays", and the more that cities use excessive emission rights, the more ecological compensation they will pay, while the cities that save the emission rights will also receive corresponding ecological compensation. In conclusion, exploring the 
transboundary ecological compensation in Songhua River Basin plays an important role in improving the efficiency of water pollution control. However, ecological compensation in cross-border watersheds is still in its infancy in China, and there is still room for further improvement in terms of compensation subjects, standards and methods.

\section{Acknowledgments}

This research was financially supported by funding from the National Social Science Foundation of China (NO.17BGL204) and the Philosophy \& Social Science Project of Heilongjiang Province (NO.16JYB04).

\section{References}

[1] Zhang Jie, Mao Ting, Qian Wei. Multi - agent Negotiation Model of Ecological Compensation for Transboundary Water Pollution in Watershed [J]. Science and Technology Management Research, 2016(3):225-229,239.

[2] Wu Puzhao, Wang Qian, Economic Analysis of Emissions Trading [J]. China Population Resources and Environment, 2010(S2):55-58.

[3] Du Jiang, Luo Jun. Agricultural Economic Growth and Input of Polluting Factors - Empirical Analysis Based on Minimalist and Structural Models [J]. Economic Review, 2013(3):56-65,117.

[4] Grossman G M, Krueger A B. Environmental Impacts of a North American Free Trade Agreement [J]. Social Science Electronic Publishing, 2000, 8(2):223-250.

[5] Sun Zhenjia, Zhang Xiangxian. Research on Enterprise Patent Level Measurement for Technology Innovation [J]. Journal of Intelligence, 2015(3):71-76.

[6] Jin Shuai. Research on Emission Trading Based on Calculation Experiments [D]. Nanjing University, 2011. 